\section{EL PERSONAJE TIPIFICADO DEL ALAZÓNEN LA COMEDIA ARISTOFÁNICA Y SUS ANTECEDENTES HOMÉRICOS}

\author{
María Jimena Schere* \\ Recebido em: 14/10/2018 \\ Aprovado em: 16/03/2019
}

RESUMEN: El tópico del alazón tiene numerosos antecedentes en la tradición literaria griega. La épica homérica conserva su registro más antiguo en el par cómico conformado por el héroe burlador Odiseo y sus antagonistas presuntuosos, Tersites e Iro. La comedia adopta el tipo cómico de fanfarrón para la construcción de sus antagonistas. El héroe retoma la figura tradicional del burlador astuto, presente en la épica y en la fábula, mientras que su antagonista representa un personaje de inteligencia inferior a la del héroe, que incurre en la petulancia. La base tradicional del tópico positivo del héroe burlador y del tópico negativo del arrogante burlado facilita que el espectador ateniense tome partido por el héroe y rechace la postura del antagonista. El tópos del fanfarrón colabora así en la comedia con el ataque satírico y facilita la degradación del personaje antagonista y de la postura que representa a los ojos del espectador ateniense.

PALABRAS-CLAVE: Alazón; par cómico; épica; comedia aristofánica.

\section{THE TYPIFIED CHARACTER OF THE ALAZON IN ARISTOPHANIC COMEDY AND ITS HOMERIC ANTECEDENTS}

* Instituto de Investigaciones en Humanidades y Ciencias Sociales, Universidad Nacional de La Plata (IdIHCSCONICET). Universidad de Buenos Aires. Universidad Nacional Arturo Jauretche. jimenaschere@hotmail.com

ABSTRACT: The topic of the alazon has numerous antecedents in Greek literary tradition. The Homeric epic retains its oldest manifestation in the comic pair conformed by the mocker hero Odysseus and his presumptuous antagonists, Thersites and Iro. The comedy adopts the comic type of braggart for the construction of its antagonists. The hero takes up the traditional figure of the cunning mocker, present in the epic and in the fable, while his antagonist represents a character of intelligence inferior to that of the hero, who shows his petulance. The traditional basis of the positive topic of the mocking hero and the negative topic of the 
mocked arrogant makes easier to take sides with the hero and reject the antagonist's position. The topic of the braggart collaborates in the comedy with the satirical attack and facilitates the degradation of the antagonist character and the posture that he represents in the opinion of the Athenian spectator.

KEYWORDS: Alazon; comic couple; epic; aristophanic comedy.

\section{INTRODUCCIÓN}

L

a épica homérica, a pesar de su tono dominantemente serio, no está exenta de comicidad. La crítica ha destacado de manera recurrente la presencia del humor en los episodios de Tersites (Ilíada, II. 211-77) y de Iro (Odisea, XVIII. 1-116), entre otros. Estos dos personajes presentan algunos rasgos comunes; en particular, ambos son retratados como individuos antiheroicos y presuntuosos, que se oponen a un antagonista superior (Odiseo) y que terminan vencidos, burlados y encarnizados por el héroe.

Podemos observar que en la comedia de Aristófanes este esquema binario encuentra amplio desarrollo. El héroe cómico es un burlador astuto, cuyo modelo paradigmático es Odiseo; el antagonista aristofánico, por su parte, suele encarnar el papel del alazón (fanfarrón, impostor).

El estudio sobre los antecedentes homéricos de los personajes protagonistas de la comedia ha sido abordado por la crítica aristofánica. Whitman ha advertido que el héroe cómico aristofánico, así como Odiseo, se caracteriza por su agudeza carente de escrúpulos. ${ }^{1}$ Sin embargo, es preciso notar que la raigambre homérica de los protagonistas aristofánicos no se limita a la construcción del héroe cómico, sino que incide también en la elaboración de su antagonista. El héroe cómico y su oponente constituyen en la comedia un par cómico convencional, con características estereotipadas, que encuentra su antecedente conservado más lejano en la épica homérica: un héroe burlador y un rival burlado, cuya presunción queda en ridículo frente a la superioridad del héroe. ${ }^{2}$ En este trabajo nos proponemos aportar a la discusión y explorar los antecedentes tradicionales del personaje, en particular, su conexión con los pares cómicos homéricos.

\section{EL ALAZÓN EN LA TRADICIÓN LITERARIA}

En el canto II de Ilíada, el personaje de Tersites se enfrenta con el rey Agamenón y cuestiona su autoridad. Ante su actitud, Odiseo reprende a Tersites verbalmente y le asesta un golpe con el cetro provocando la risa del ejército (v. 211-77). Tersites constituye una

\footnotetext{
${ }^{1}$ Whitman (1964, p. 28).

${ }^{2}$ Whitman (1964), por ejemplo, contempla el carácter cómico de Tersites, pero lo vincula al héroe cómico. En nuestra opinión, Tersites se relaciona claramente con el antagonista del héroe y el héroe cómico se asimila a la figura del astuto Odiseo. Sobre el humor en Tersites e Iro, cf. Hunt (1890), Ramos Jurado (1987), Thalmann (1988), Halliwell (1991, p. 281), Nagy (1999, p. 262), Rosen (2007, p. 67-116).
} 
figura ridiculizada desde la presentación del personaje, que resalta de manera caricaturesca la fealdad de su aspecto físico: Tersites es el "hombre más feo que llegó a Ilión” (v. 216), ${ }^{3}$ patizambo, cojo, encorvado, con cabeza puntiaguda y cabello ralo (v. 216-19). Por su fealdad y su falta de poder resulta un personaje opuesto a sus antagonistas, Agamenón y Odiseo, y contrario a los ideales heroicos. Tersites concentra, además, otra serie de rasgos negativos: Odiseo lo acusa de ser un "hablador sin juicio" (v. 246) y "el peor de los mortales" (v. 248). Por su parte, condena en forma expresa su "ánimo arrogante” ( $\theta 0 \mu$ ò $\alpha_{\alpha} \gamma \tilde{v} v \omega \rho,{ }^{4}$ v. 276) y su enfrentamiento con los reyes (v. 277). En definitiva, Tersites es el blanco cómico del episodio y la contraparte devaluada del héroe Odiseo que lo convierte en objeto de mofa. Odiseo, acorde con su caracterización habitual, constituye el burlador y Tersites el burlado. Además, Tersites representa el antecedente más antiguo del tipo cómico del arrogante: se atribuye una jerarquía que no le corresponde, se atreve a disputar con sus superiores y termina cómicamente rebajado y degradado por el escarnio físico y la risa del ejército.

Odisea también presenta un antecedente del tipo cómico del fanfarrón en la figura del mendigo Iro (Od. 18.1-116). El héroe regresa a Ítaca, disfrazado de mendigo, y se encuentra con Iro en las puertas del palacio. El mendigo intenta expulsarlo del lugar y lo desafía a medirse con él en un enfrentamiento físico; sin embargo, al ver los brazos desnudos del falso mendigo Odiseo, intenta retroceder, acobardado, pero los servidores lo conducen por la fuerza. Finalmente, se desarrolla la pelea, Iro termina apaleado por su adversario y provoca las risas de todos los pretendientes (v. 100).

La caracterización de Iro resulta negativa desde el comienzo y destaca su voracidad y su propensión a la bebida (v. 3). Asimismo, se señala su debilidad física (v. 3-4), en contraste con el cuerpo de Odiseo (v. 66-69). ${ }^{5}$ Iro constituye la contracara antiheroica de Odiseo: débil y carente de poder como Tersites. Además, el mendigo representa claramente el tipo cómico del fanfarrón: el pretendiente Antínoo lo llama de manera explícita "ßovyóiős" (fanfarrón', 'jactancioso', v. 79) por mostrarse acobardado al descubrir el cuerpo robusto de Odiseo debajo de los harapos, luego de haberlo desafiado a batirse con él. Odiseo también le reprocha su

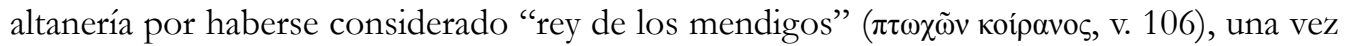
que lo ha vencido en la pelea.

En este par cómico, Odiseo resulta nuevamente el burlador e Iro, el personaje burlado, engañado y vencido por el héroe. Además, Iro retoma la figura del fanfarrón, que se opone a un antagonista superior en fuerza y en astucia y que termina degradado y convertido en objeto de burla por los pretendientes, así como Tersites desencadena la risa de la tropa ante la golpiza de Odiseo.

\footnotetext{
${ }^{3}$ Utilizamos la edición de Monro y Allen (1902). Las traducciones son nuestras.

${ }^{4} \mathrm{El}$ término $\dot{\alpha} \lambda \alpha \zeta \dot{\omega} \omega$ no aparece atestiguado hasta el siglo V (cf. Bonfante, 1936, p. 77; Beta, 2004, p. 237).

${ }^{5} \mathrm{Od}$. 18.66-69: "Odiseo / se ciñó los genitales con sus harapos y quedaron a la vista sus muslos / bellos y grandes y sus hombros anchos / y su pecho y brazos robustos”. Utilizamos la edición de Murray (1919).
} 
Sin duda, el fanfarrón constituye un tipo folklórico tradicional que presenta manifestaciones en otros géneros. La épica homérica representa el registro más antiguo, pero también se observan antecedentes en la fábula, el yambo y el drama siciliano.

En la fábula encontramos manifestaciones directas del tópico como en "El fanfarrón" (Ch. 51), que ridiculiza la jactancia vana de un competidor del pentatlón. Son muchas las fábulas que involucran el par cómico convencional del burlador y el burlado y que tienen como blanco cómico central las pretensiones infundadas de un personaje. Tomemos por ejemplo "El burro que llevaba una estatua" (Ch. 266):

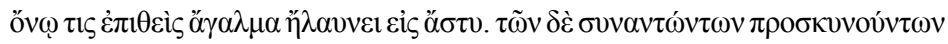

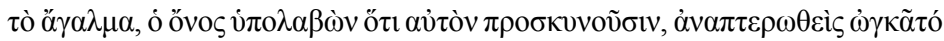

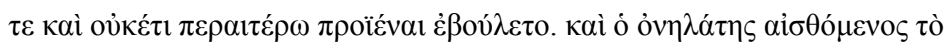

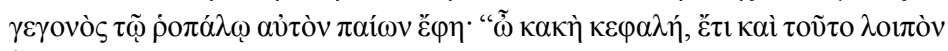

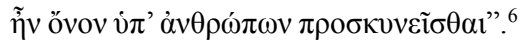

Un hombre, habiendo cargado sobre un burro una estatua de un dios, lo conducía hacia la ciudad. Como los que se lo encontraban se prosternaban ante la estatua, el burro -creyendo que se prosternaban ante él- se puso a rebuznar orgulloso y ya no quería avanzar más. $\mathrm{El}$ arriero, que se dio cuenta de lo que pasaba, mientras lo golpeaba con el garrote, le dijo: "Mala cabeza, no faltaba más que un burro adorado por los hombres".

En esta fábula, el personaje del arriero representa el burlador, que deja en ridículo el absurdo orgullo del burro, golpeado y ridiculizado por su oponente. El blanco cómico central, como en los pares cómicos homéricos, está ocupado por el alazón que se arroga una posición equivocada.

Los ejemplos se multiplican en el género. En la fábula "El cuervo y la zorra" (Ch. 165), la zorra incita con falsos elogios a cantar al cuervo, que abre el pico y deja caer un pedazo de carne. La zorra hurta la carne y se burla de las falsas pretensiones del cuervo. La zorra resulta la hábil engañadora y burladora del ingenuo cuervo, blanco cómico de la narración. También en "La zorra y el mono elegido rey" (Ch. 38) la zorra ridiculiza la falta de inteligencia del mono, que se considera capacitado para reinar sin fundamento. Otra fábula de esta serie, protagonizada por la zorra, habitual burladora del par cómico, representa "La zorra y el mono discuten por su prosapia" (Ch. 39): el mono al pasar por un cementerio se vanagloria de sus antepasados; pero la zorra desenmascara su engaño y su arrogancia pronunciando un dicho ingenioso, como en los ejemplos anteriores: "Pues miente cuanto

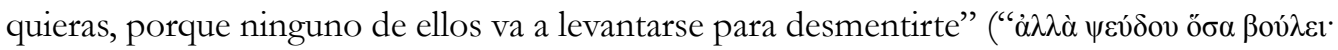

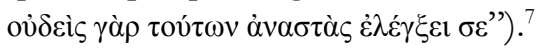

\footnotetext{
${ }^{6}$ Utilizamos la edición de Chambry (1927).

${ }^{7}$ Para un estudio más detallado sobre el par cómico en la fábula, véase Schere (2014).
} 
Esta fábula es retomada por Arquíloco en el fragmentario Epodo VII, según la reconstrucción de Rodríguez Adrados. ${ }^{8}$ Arquíloco emplea la fábula y sus tópicos de burla para atacar a blancos concretos, presuntamente de naturaleza extratextual. ${ }^{9}$ Pero la poesía yámbica también incorpora el tópico en otros poemas desligados de la tradición fabulística. El tópos específico del "general fanfarrón” encuentra un antecedente en la poesía de Arquíloco (fr. 166 Rodríguez Adrados): ${ }^{10}$

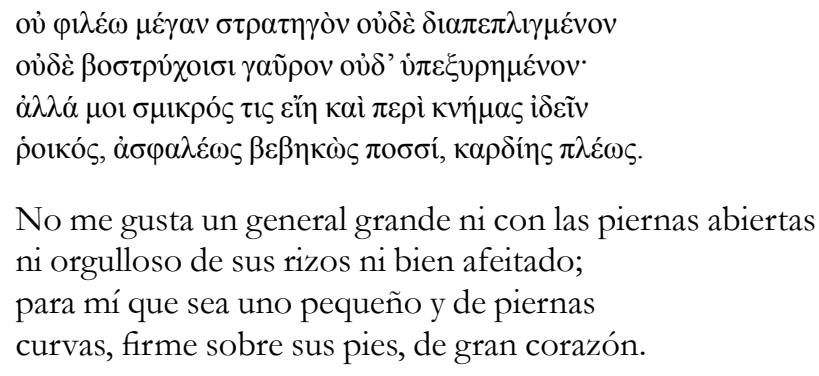

El tópos particular del "general fanfarrón", de carácter militar, se puede incluir dentro del tópico más global del alazón asociado al par cómico tradicional (Iro, Tersites y los personajes de la fábula). Sin embargo, cabe destacar que el tópico del "general fanfarrón" tiene menos tradición que el tópico genérico que encuentra registros en la épica.

También en el drama siciliano de Epicarmo, género escasamente atestiguado, se ha señalado la presencia de múltiples personajes cómicos tipificados como el parásito, el ebrio, el filósofo, el rústico, el Heracles glotón, el astuto Odiseo, los dioses burlescos. ${ }^{11}$ En particular, Pickard-Cambridge observa que la figura del alarón es objeto de burla en sus comedias. ${ }^{12}$

El personaje del alazón, en suma, encuentra sus registros más antiguos en la épica homérica, género en el que el personaje constituye una pareja cómica con el héroe burlador. En la fábula encontramos una estructura doble semejante, constituida por el personaje burlador, habitualmente la zorra, ${ }^{13}$ y su oponente convertido en objeto de burla por su vana presunción. Asimismo, el yambo, por la incorporación de la fábula o de manera autónoma, y el drama siciliano, géneros antecesores directos de la comedia, explotan este tipo cómico.

La filosofía antigua también se ha ocupado del tema. Aristóteles define en Ética Nicomaquea la figura del alazón: el $\dot{\alpha} \lambda \alpha \zeta \omega ́ v$ es aquel que se arroga una reputación que no tiene o en mayor medida de la que tiene y lo opone a la figura del cîp corresponde o le resta importancia (4.7.1127a21-23).

\footnotetext{
${ }^{8}$ Rodríguez Adrados (1981).

${ }^{9}$ Cf. Rosen (1988, p. 31-33), van Dijk (1997), Carey (2009, p. 159-60).

${ }^{10}$ Utilizamos la edición de Rodríguez Adrados (1981).

${ }^{11}$ Pickard-Cambridge (1997, p. 410).

${ }^{12}$ Pickard-Cambridge (1997, p. 405). El autor sostiene que no se puede determinar el grado preciso en que Epicarmo influenció en la comedia ática (1997, p. 410).

${ }^{13}$ La zorra astuta es un personaje dominante en la fábula griega (Rodríguez Adrados, 1979, p. 172).
} 
Sin hacer referencia a caracteres específicos, Platón asocia lo cómico con la

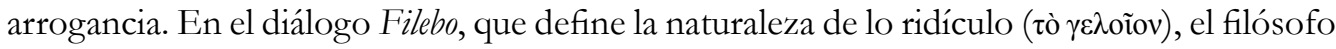
sostiene que lo ridículo tiene origen en el vicio de la ignorancia de sí, esto es, la incapacidad de poner en práctica el mandato délfico " $\gamma v \tilde{\omega} \theta t$ c $\sigma \alpha v \tau o ́ v "$ " "conócete a ti mismo")..$^{14}$ La risa es originada por la presunción de ciertos individuos de ser más ricos de lo que son en realidad, de ser más bellos, o de tener más virtud -en especial, más sabiduría- de la que efectivamente tienen. En suma, la arrogancia se considera un vicio y, además, una falta intelectual que convierte en objeto de burla a un individuo.

Si tomamos los ejemplos de la tradición literaria, podemos observar que efectivamente los arrogantes se caracterizan por su inferioridad intelectual, ingenuidad o menor perspicacia que sus oponentes, que los lleva a considerarse por encima de sus posibilidades. El burlador, por su parte, es el encargado de rebajarlo por medio de la risa. El pensamiento filosófico sobre el alazón coincide con su representación devaluada en la tradición literaria, que lo convierte en blanco de burla.

\section{EL ALAZÓN EN LA COMEDIA DE ARISTÓFANES}

A partir de la diferenciación aristotélica entre eǐp $\omega v$ y à̉ $\lambda a \zeta \omega \omega v$, Cornford ha sostenido que el héroe cómico aristofánico es un bufón irónico, un eịp $\omega v$ (un hombre que pretende tener

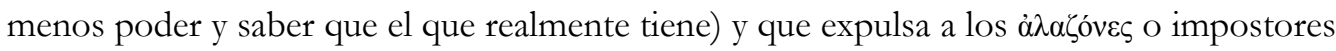
que intentan participar de su régimen. ${ }^{15}$ También considera que el antagonista es en un sentido amplio un $\dot{\alpha} \lambda \alpha \zeta \omega^{\prime} v^{16}{ }^{16}$

Esta perspectiva ha sido retomada por McLeish quien reafirma que los antagonistas

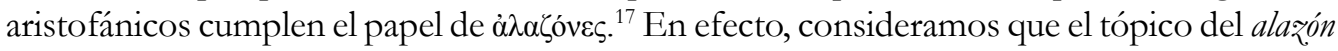
no solo está presente en personajes circunstanciales de la comedia, sino que adquiere especial relevancia en la construcción de su antagonista central, sobre todo en la obra temprana.

La crítica ha analizado ampliamente la figura del general Lámaco, rival del héroe Diceópolis en Acarnienses, como una figura paradigmática del alazón y un antecedente del miles gloriosus. ${ }^{18}$ Lámaco, principal representante de la postura en favor de la guerra, encarna el personaje de un general arrogante por su ostentosa armadura y su lenguaje grandilocuente.

\footnotetext{
${ }^{14}$ Filebo 48a-50a. Sobre lo ridículo en el Filebo, véase Schulthess (2000).

${ }^{15}$ Conford [1914] (1993, p. 119-22).

${ }^{16}$ Conford [1914] (1993, p. 134); cf. Gil Fernández (1981-1983). Esta postura ha sido cuestionada por algunos autores como Hubbard (1991, p. 69) que interpreta que el héroe aristofánico tiene tanto

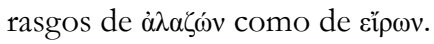

${ }^{17}$ McLeish (1980, p. 54).

${ }^{18}$ Edmunds (1980, p. 13-14) y Mastromarco (2002, p. 211-16), entre otros, interpretan que el personaje representa la figura del miles gloriosus. MacDowell (1990, p. 207-208) observa que el término "alazón" se refiere en la obra a los embajadores. Lámaco no es mencionado bajo este rótulo. Sin embargo, compartimos con gran parte de la crítica que Lámaco, por sus características, encuadra en el tipo cómico.
} 
El héroe cómico Diceópolis se burla de él de manera expresa haciendo referencia a su petulancia, por ejemplo, cuando se refiere a las plumas de "pájaro-fanfarrón” (v. 589) que adornan su casco.

La principal escena agonal que enfrenta al héroe Diceópolis con su antagonista Lámaco (v. 572-627) presenta resonancias de los pares homéricos y de la estructura binaria tradicional que opone un héroe astuto a un antagonista presuntuoso. En particular, se pueden observar sobre todo correspondencias con el episodio de Iro. Lámaco se enfrenta con el astuto Diceópolis, que se encuentra disfrazado de mendigo, como Odiseo en su llegada a Ítaca. ${ }^{19}$ Lámaco ignora la identidad del héroe, conocida para el público, y resulta el blanco del engaño y de la burla al igual que Iro. Además, subestima a su oponente, ${ }^{20}$ dejando al descubierto su vana arrogancia, y termina inexorablemente derrotado por él. Finalmente, el coro se inclina por tomar partido por Diceópolis, vencedor en la escena agonal, como los pretendientes en la escena homérica.

Más allá de las alusiones concretas, como el disfraz de mendigo, entendemos que el par homérico incide, sobre todo, en la elaboración de la estructura del par aristofánico y de sus rasgos constitutivos. Esto significa que el comediógrafo construye sus personajes protagonistas siguiendo el esquema homérico -folklórico y tradicional-de contraponer las figuras convencionales del astuto y el fanfarrón.

Por otra parte, el uso del tópico del alazón, favorece la estrategia argumentativa de la pieza. Mediante su implementación, el principal contradiscurso atacado en la pieza, la postura belicista, adquiere mayor eficacia. El uso del tópos opera como un conector intertextual que relaciona el personaje de Lámaco con figuras negativas de la tradición literaria (Tersites, Iro, los personajes negativos de la fábula, etc.). Asimismo, la carga negativa del tópico y sus personajes asociados permiten potenciar el ataque cómico contra el personaje de Lámaco y le aporta un aval tradicional a la sátira. Su figura queda asociada a los ojos del espectador ateniense con una serie de ideas negativas que pertenecen al acervo tradicional de la cultura griega: el arrogante, el impostor malvado, el tonto ingenuo burlado por la capacidad superior de un héroe burlador astuto.

Sin embargo, no sólo Lámaco se encuadra en el tópico; en las comedias tempranas los antagonistas del héroe cómico suelen caracterizarse también por su presunción, que se revela vana al ser finalmente derrotados por el héroe burlador. En la comedia Caballeros Paflagonio, que representa al orador Cleón, hace gala de su inescrupulosidad que le permite dominar a la Asamblea y se jacta de su habilidad oratoria. ${ }^{21}$ A pesar de su capacidad de engaño y de la manipulación del pueblo, el héroe Morcillero se revela finalmente más hábil que su rival, gana el favor del pueblo y se impone como vencedor definitivo. En el caso de

\footnotetext{
${ }^{19}$ Whitman (1964, p. 28) ha sido el primero en observar los paralelismos entre el héroe cómico aristofánico y Odiseo. Esta hipótesis ha sido retomada por otros autores como Harriot (1982, p. 37) y de Lamberterie (1998, p. 33). Harriott, por ejemplo, observa específicamente la similitud del disfraz de mendigo.

${ }^{20}$ Lámaco increpa a Diceópolis diciéndole: “¿Tú, siendo un mendigo, te atreves a hablarme?” (v. 577).

${ }^{21}$ P. ej. Caballeros 342-58.
} 
Cleón, el término alazón y léxico relacionado se emplea de manera expresa. ${ }^{22}$ Nuevamente, el blanco central de la obra, el orador Cleón, es degradado mediante el tópico tradicional.

Otro buen ejemplo del uso del tópico en la obra aristofánica constituye la comedia Paz. En Paz el campesino Trigeo logra burlar e imponerse sobre su poderoso antagonista Pólemos, personificación de la guerra. El temible Pólemos esgrime sus amenazas presuntuosas contra Trigeo y los griegos, pero termina derrotado por el héroe. El argumento de Pazsigue de cerca la fábula "El escarabajo y el águila" (Ch. 4), citada expresamente en los versos 127 34 de la obra, que pone en ridículo la altanería del águila, vencida por el débil escarabajo. Pólemos se asimila claramente a la figura del águila que subestima a su pequeño adversario.

Otro aspecto destacable de la figura de Pólemos es la suma de paralelismos con el personaje de Lámaco. Tanto Lámaco como Pólemos emplean términos de raigambre homérica, que adquieren una modalidad paródica en el contexto de la comedia. Pólemos usa, por ejemplo, el epíteto homérico $\pi \mathrm{o} \lambda \nu \tau \lambda \eta \dot{\mu} \mu \nu$ ("muy sufrido", "de gran resistencia", v. 236). ${ }^{23}$

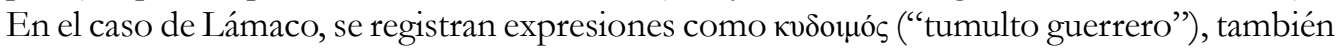
de procedencia homérica. ${ }^{24} \mathrm{El}$ vocabulario épico establece una relación intertextual entre los géneros y una vinculación entre los dos personajes. Además, el héroe Trigeo se refiere a Pólemos con un epíteto tradicional relacionado con Ares ( $\tau \alpha \lambda \alpha v ́ \rho ı$ s, v. 241), utilizado en Acarnienses para caracterizar a Lámaco. ${ }^{25}$ En efecto, tanto Lámaco como Pólemos son antagonistas relacionados con la posición belicista, se caracterizan ambos por emplear un lenguaje épico, altisonante y presuntuoso, por recibir epítetos comunes y por responder, en definitiva, al tipo cómico del alazón. Las dos figuras subestiman a su adversario, lo tratan con arrogancia y terminan derrotados por el héroe, que los supera en astucia.

En las comedias tempranas de Aristófanes, podemos observar entonces de manera recurrente la prevalencia del esquema convencional del par cómico, conformado por un héroe burlador que se impone sobre su antagonista presuntuoso: Lámaco, Paflagonio, Sócrates, ${ }^{26}$ Pólemos presentan rasgos del tipo cómico. En todos los casos, estos personajes constituyen el eje central de la burla y del contradiscurso atacado en la pieza, así como Tersites e Iro representan valores contrarios a los ideales épicos.

\footnotetext{
${ }^{22}$ Por ejemplo, en el verso 269 el coro de caballeros lo llama “alazón”, referido más bien a su capacidad

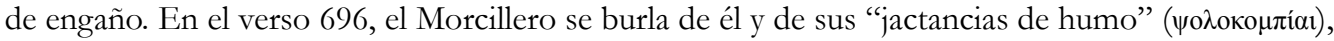
clara referencia a su fanfarronería. Sobre el término y léxico afín referido a Cleón y a personajes circunstanciales de la comedia, cf. Mac Dowell (1990), Major (2006, p. 135).

${ }^{23}$ Ilíada VII.152; Odisea XIII.319. El personaje amenaza con ejercer su poder destructivo sobre las ciudades griegas: “ $\mathrm{Oh}$ mortales, mortales, mortales de gran resistencia ( $\pi \mathrm{o} \lambda v \tau \lambda \hat{\mu} \mu \omega v)$ !” (v. 236). Cf. Moulton (1981, p. 86, n. 27).

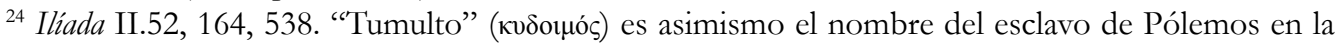
comedia Paz,(Olson, 2002, p. 223).

${ }^{25}$ Olson (1998, p. 117).

${ }^{26}$ También en Nubes se ha señalado la presencia del tópico del alazón en el personaje de Sócrates (Grene, 1937, p. 96-97 y 106). Sócrates representa en la obra la figura del intelectual petulante y la educación de corte sofístico.
} 
La crítica ha debatido ampliamente sobre los antecedentes del alazón de comedia. Sobre este tema, se ha prestado especial atención a la figura particular del miles gloriosus y a su relación con el general Lámaco, el antagonista de Acarnienses. La hipótesis de Wisk conjetura que el tópico del miles gloriosus probablemente haya llegado a la comedia a través del drama siciliano. ${ }^{27}$ Webster pone en duda esta hipótesis y sostiene, en cambio, que la aparición del soldado como figura histórica de la comedia se produce a partir del personaje de Lámaco en Acarnienses. ${ }^{28}$ Mastromarco ha observado, asimismo, que la figura de Lámaco constituye el primer testimonio del "soldado fanfarrón" conservado en la comedia. Según el autor, el nombre parlante de Lámaco y su presunción lo asimilan al tópico del miles gloriosus, presente en el teatro cómico posterior. Mastromarco también destaca que algunos rasgos del miles gloriosus (i.e. el nombre parlante, la presunción y la cobardía) encuentran un antecedente en el Tersites homérico. ${ }^{29}$

Cabe observar que si bien se han discutido los antecedentes literarios del "soldado fanfarrón”, no se ha señalado la relación entre Lámaco y el tópos más amplio del fanfarrón homérico. El tópico del miles gloriosus es una manifestación particular, de carácter militar, del tópico genérico del fanfarrón. A nuestro modo de ver, el antagonista fanfarrón de la comedia aristofánica excede ampliamente la figura del miles gloriosus y tiene raigambre homérica en los pares cómicos de Ilíada y Odisea, como hemos visto, y en otros antecedentes tradicionales. En suma, las duplas cómicas homéricas y tradicionales y, en particular, la construcción del blanco cómico central bajo la figura del alazón colabora en la construcción del esquema binario aristofánico y favorece sus efectos argumentativos.

\section{Conclusiones}

El tópico del alazón tiene numerosos antecedentes en la tradición literaria griega. La épica homérica conserva su registro más antiguo en el par cómico conformado por el héroe burlador Odiseo y sus antagonistas presuntuosos, Tersites e Iro, personajes antiheroicos, opuestos a los valores aristocráticos del héroe. Si bien la crítica se ha centrado fundamentalmente en los registros del tópico particular del miles gloriosus, el alazón no necesariamente se encuentra ligado en la tradición a una figura de carácter militar, como ocurre por ejemplo con el caso del mendigo Iro.

La presunción en la tradición literaria griega y en el pensamiento filosófico aparece como un rasgo negativo de carácter sujeta al escarnio de la risa. El propio Platón ubica la arrogancia en su definición de lo cómico, ligada a la incapacidad intelectual de la ignorancia de sí. En los casos registrados en la épica, en la fábula y en los antagonistas aristofánicos, los fanfarrones se caracterizan en efecto por ser intelectualmente inferiores a su oponente que se impone como burlador y vencedor. La figura del tonto ingenuo constituye un tópico cómico tradicional por sí mismo, con registros en la épica, por ejemplo en el cómico personaje del

\footnotetext{
${ }^{27}$ Wisk (1921, p. 5-6).

${ }^{28}$ Webster (1953, p. 64). Sobre esta discusión, véase Gil Fernández (1975, p. 74-78).

${ }^{29}$ Mastromarco (2009).
} 
Cíclope del canto IX de Odisea, que resulta engañado y burlado por el astuto Odiseo. En definitiva, los tópicos del tonto ingenuo, carente de perspicacia intelectual, y el del fanfarrón se encuentran asociados a figuras cómicas tanto en la épica como en otros géneros. En la fábula, en particular, el animal burlado por su oponente carece de inteligencia y se arroga también cualidades que no posee; es decir que la arrogancia y la falta de inteligencia se conjugan en el blanco del par cómico.

La comedia adopta el tipo cómico del fanfarrón para la construcción de sus antagonistas. El héroe retoma la figura tradicional del burlador astuto, presente en la épica y en la tradición fabulística, especialmente en el personaje de la zorra; mientras tanto, su antagonista representa un personaje de inteligencia inferior a la del héroe que se atribuye cualidades que no tiene e incurre en la petulancia. La base tradicional del tópico positivo del héroe burlador y del tópico negativo del arrogante burlado facilita que el espectador ateniense tome partido por el héroe y rechace la postura del antagonista. El tópico del fanfarrón, en suma, asociado a la falta de perspicacia intelectual, colabora con el ataque satírico y facilita la degradación del personaje y la postura que representa a los ojos del espectador ateniense.

\section{REFERENCIAS}

BETA, Simone. Il linguaggio nelle commedie di Aristofane. Parola positiva e parola negativa nella comedia antica (Suppl. n. 21/22 al Bollettino dei Classici). Roma: Accademia Nazionale dei Lincei, 2004.

BONFANTE, Giuliano. Etymologie du mot grec alazon. Bulletin de la Société de Linguistique de Paris, v. 37, p. 77-78, 1936.

BURNET, John (Ed.). Plato. Platonis Opera. Philebus. Oxford: Oxford University Press, 1903. BYWATER, Ingram (Ed.). Aristotelis. Ethica Nicomachea. Oxford: Oxford University Press, 1959 [1894].

CAREY, Christopher. Iambos. In: BUDELMANN, Felix (Ed.). The Cambridge Companion to Greek Lyric. Cambridge: Cambridge University Press, 2009, p. 149-67.

CHAMBRY, Émile (Ed., trad.). Ésope. Fables. Paris: Les Belles Lettres, 1927.

CORNFORD, Francis Macdonald. The Origin of Attic Comedy. Michigan: University of Michigan Press; Ann Arbor, 1993 [1914].

DE LAMBERTERIE, Charles. Aristophane, lecteur d'Homère. In: TRÉDÉ, Monique y HOFFMAN, Philippe (Ed.). Le rire des anciens. Actes du Colloque Internacional (Université de Rouen, École normale supérieure, 11-13 janvier 1995). Paris: Presses de l'Ecole normale supérieure, 1998. p. 33-52.

EDMUNDS, Lowell. Aristophanes' Acharnians. In: HENDERSON, Jeffrey (Ed.). Aristophanes. Essays in interpretation. Cambridge: Cambridge University Press, 1980. p. 1-41. (Yale Classical Studies, 26). 
GIL FERNÁNDEZ, Luis. Comedia ática y sociedad ateniense III. Los profesionales del amor en la comedia media y nueva. Estudios Clásicos, v. 74-76, p. 59-88, 1975.

GIL FERNÁNDEZ, Luis. El ‘alazón’ y sus variantes. Estudios Clásicos, v. 25, p. 39-57, 1981 1983.

GRENE, William David. The comic technique of Aristophanes. Hermathena, v. 25, n. 50, p. $87-125,1937$.

HALLIWELL, Stephen. The Uses of Laughter in Greek Culture. The Classical Quarterly, v. 41, p. 279-96, 1991.

HARRIOTT, Rosemary M. The Function of the Euripides Scene in Aristophanes' 'Acharnians'. Greece \& Rome, v. 29, n. 1, p. 35-41, 1982.

HUBBARD, Thomas K. The Mask of Comedy. Aristophanes and the Intertextual Parabasis. Ithaca: Cornell University Press, 1991.

HUNT, Irving. Homeric Wit and Humor. Transactions of the American Philological Association, v. 21, p. $48-58,1890$.

MACDOWELL, Douglas. The Meaning of $\alpha \lambda \alpha \zeta \omega$ v. In: CRAIK, E. M. (Ed.). Owls to Athens: Essays on Classical Subjects Presented to Sir Kenneth Dover. Oxford: Clarendon Press; New York: Oxford University Press, 1990. p. 287-94.

MAJOR, Wilfred E. Aristophanes and "Alazoneia": Laughing at the Parabasis of the "Clouds". The Classical World, v. 99, n. 2, p. 131-44, 2006.

MASTROMARCO, Giuseppe. La maschera del miles gloriosus: dai Greci a Plauto. In: RAFFAELLI, R.; TONTINI, A. (Ed.). Lecturae Plautinae Sarsinates, XII, Miles gloriosus. Urbino: QuattroVenti, 2009.p. 17-40.

MASTROMARCO, Giuseppe. Onomasti komoideîn e spoudaiogeloin. In: ERCOLANI, A. (Ed.). Spoudaiogeloion. Form und Funktion der Verspottung in der aristophanischen Komödie. Stuttgart: Verlag J. B. Metzler, 2002. p. 205-23.

MCLEISH, Kenneth. The Theatre of Aristophanes. London: Thames and Hudson, 1980.

MONRO, David B.; ALLEN, Thomas W. (Ed.). Homero. Opera. Oxford: Oxford Clarendon Press, 1939 [1902]. 2 v.

MOULTON, Carroll. Aristophanic Poetry. Göttingen: Vandenhoeck und Ruprecht, 1981.

MURRAY, Augustus Taber (Ed.). Homer. The Odyssey. London: William Heinemann, 1919.

NAGY, Gregory. The best of the Achaeans. Concepts of the hero in Archaic Greek poetry. Baltimore: Johns Hopkins University Press, 1999.

OLSON, Douglas. S. (Ed., com.). Aristophanes. Peace. Oxford: Clarendon Press, 1998. 
OLSON, Douglas. S. (Ed., com.). Aristophanes. Acharnians. Oxford: Oxford University Press, 2002.

PICKARD-CAMBRIDGE, Arthur W. Dithyramb, Tragedy and Comedy. Oxford: Clarendon Press, 1997 [1927].

RAMOS JURADO, Enrique Ángel. Homero precursor de la tragedia y de la comedia, Minerva, v. 1, p. $75-80,1987$.

RODRÍGUEZ ADRADOS, Francisco. Historia de la fábula greco-latina (1). Introducción y de los orígenes a la edad helenística. Madrid: Editorial de la Universidad Complutense, 1979.

RODRÍGUEZ ADRADOS, Francisco. (Ed., com.). Liricos griegos. Elegiacos y yambógrafos arcaicos. Madrid: Consejo Superior de Investigaciones Científicas, 1981.

ROSEN, Ralph Mark. Old Comedy and the Iambographic Tradition. Atlanta: Scholars Press, 1988.

ROSEN, Ralph Mark. Making Mockery. The Poetics of Ancient Satire. Oxford: Oxford University Press, 2007.

SCHERE, María Jimena. El par cómico en la fábula y su proyección sobre el par aristofánico. Myrtia. Revista de Filología Clásica, v. 19, p. 39-67, 2014.

SCHULTHESS, Daniel. Rire de l'ignorance? (Platón, Philébe 48a-50e). In: DESCLOS, MarieLaurence (Ed.). Le rire des Grecs. Anthropologie du rire en Grèce ancienne. Grenoble: Jérome Million, 2000. p. 309-18.

THALMANN, William G. Thersites: Comedy, Scapegoats, and Heroic Ideology in the Iliad. Transactions of the American Philological Association, v. 118, p. 1-22, 1988.

VAN DIJK, Gert-Jan. Ainoi, Logoi, Mythoi: Fables in Archaic, Classical, and Hellenistic Greek Literature. Leiden: Brill, 1997.

WHITMAN, Cedric H. Aristophanes and the Comic Hero. Cambridge, MA: Harvard University Press, 1964.

WYSK, Hans. Die Gestalt des Soldaten in der Griechisch-römischen Kömodie. Giessen: Herr, 1921. 